\title{
Vertical Displacements Measuring Methods During Bridge Load Tests
}

\author{
Boštjan Kovačič ${ }^{1, *}$, Ante Marendić ${ }^{2}$, Rok Kamnik ${ }^{1}$, Mikhail Volkov ${ }^{3}$ and Vera Roy ${ }^{3}$ \\ ${ }^{1}$ University of Maribor, SI 2000 Smetanova 17, Maribor, Slovenia \\ ${ }^{2}$ University of Zagreb, hr 10000 Kačićeva 26, Zagreb, Croatia \\ ${ }^{4}$ Peter the Great St. Petersburg Polytechnical University, 195251 Politekhnicheskaya str., 29, Saint- \\ Petersburg, Russia
}

\begin{abstract}
This article introduces the use of the GNSS method for the load testings of bridge structures. We know that there area lot of methods by which you can determine vertical displacement. However, as new bridge constructions are constructed over almost impossible and inaccessible gorges and valleys, the classic measurements method do not allow us to determine vertical displacement so reliably any more or they are very timeconsuming. The GNSS method is well known but there are difficulties when determining the altitude component of this method, which is rather questionable. For this purpose, the methods were tested as practical examples in which some difficulties were encountered, so subsequently another test recording was performed of altitude changes using this method.
\end{abstract}

\section{Introduction}

Load tests are needed in order to assess the behavior of any new building or determine the state of existing facilities before/after any rehabilitation. They enable us to verify the theoretical assumptions, as well as determining use factors which so affect the capacity of the construction they cannot be predicted theoretically. When observing a bridge structure, vertical displacements are very important because they have the biggest impact on the structure and its eventual deformation, while the horizontal displacements are tested especially in the case of rail lines and in more demanding engineering measurements of deformation [1-16].

There are several different methods for performing load tests on bridges but, in general, it involves the placement of sensors on all critical load carrying members and electronic measurements of their individual responses as known vehicles traverse the bridge (Chowdhury and Ray 2003). The method used depends on the type of construction, accessibility, required accuracies, sensitivities and reliabilities of the used instruments.

During scientific research, the newest methods are often used for a link between the results, analysis methods and displaying the results, such as photogrammetry (Guarnieri et. al. 2004, Albert et.al. 2002, Jauregui et.al. 2003, Maas and Hampel, 2006) and laser

* Corresponding author: bostjan.kovacic@um.si 
scanning method (Gordon et.al 2004, Schäfer et.al. 2004, Fuchs et.al. 2004). A dynamic testing of bridges using geodetic equipment was considered in Marendić et. al. 2013.

During a load test all characteristic points, namely supports and midpoints of the spans of the bridge and those places where the greatest displacements are expected should be monitored. The dynamic and static loads are investigated during load testing.

Dynamic testing is performed using dynamic loads like shocks, vibrations or dynamic vibrations. For example, in bridge structures, the dynamic load is carried out by driving a fully loaded truck at the facility. According to the former JUS standard, which was valid in Slovenia prior to the introduction of EUROCOD during dynamic loading test, were mandatory for:

- measurements of vertical displacements in the middle of the selected bridge span (mid-of the span - between two supports);

- measuring of the speed of the dynamic loads (speed of the truck);

- measuring deformations in the places of expected maximum tension;

- measurements of other dynamic properties of the structure.

The dynamic part of the load test is usually performed separately, where the left and right parts of the facility is physically separated. In order to better control the speed, the direction of driving the truck at both facilities is the same. In Fig. 1 the dynamic part of the load test can be seen.

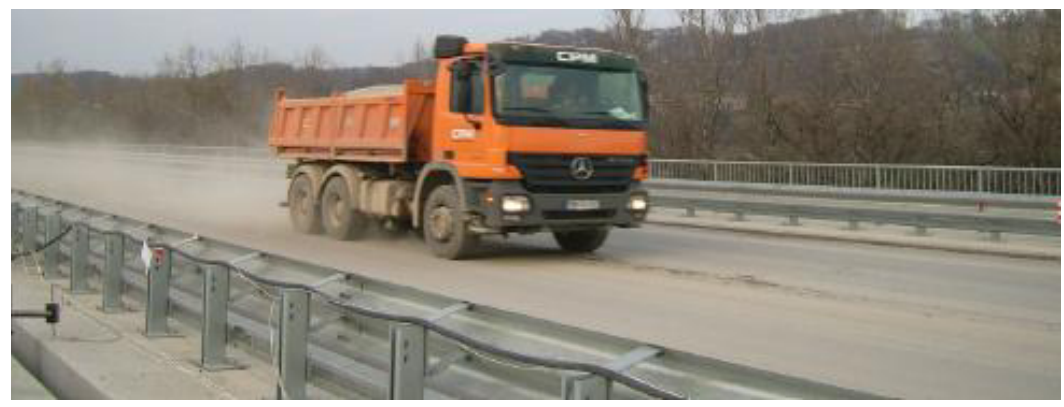

Fig. 1. Dynamic load test.

The static part of the load test is carried with an exact number of vehicles and loads, depending on the length and number of fields and supports. Usually both carriage ways burdened at the same time.

According to the former JUS standard during static load testing the following were mandatory:

- measurement of the vertical displacement in the middle of each bridge span;

- measuring the displacement of the support;

- observation of cracks;

- measuring of deformations in foreseen areas, where maximum strains are expected;

- measurement of permanent deformations and deformations after disburden in the bridge.

Static tests are performed for investigating structural behavior under static loads. When investigating this, local and general deformations are measured in order to determine the tensile forces in the structure of a particular element a construction or one of its parts. The geometry of the structure or its components changes under load. These changes are reflected as shrinking or stretching of the structure and as the relative displacement of points. The static part of the load test can be seen in Fig 2. 


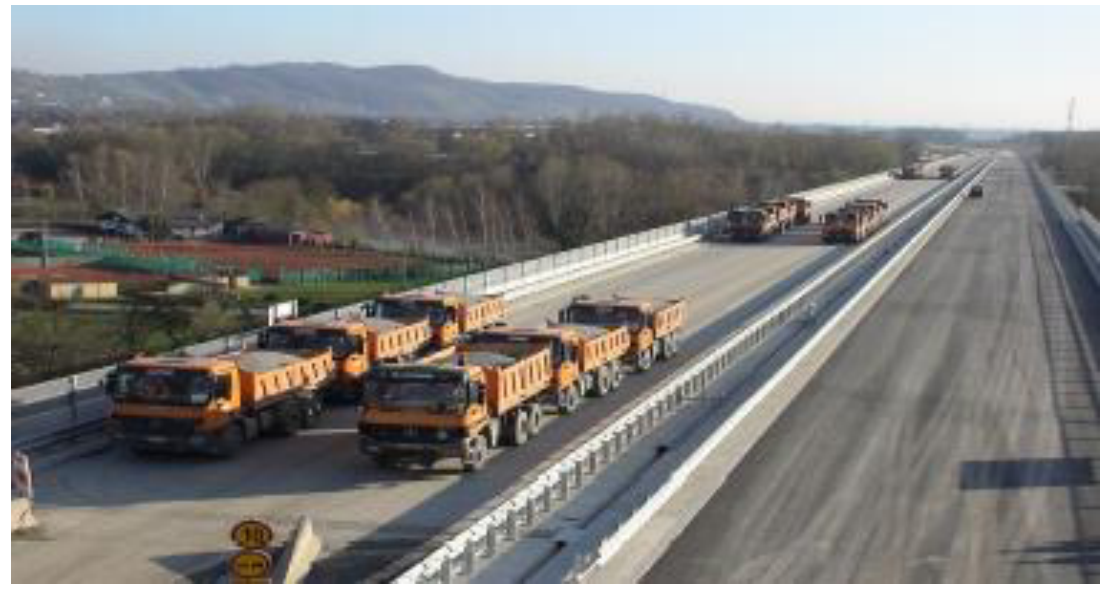

Fig. 2. Static load test.

\section{Materials and methods}

\subsection{GNSS method}

When using GNSS methods for the monitoring of vertical displacements in practice a combination of base-rover is more commonly used (base serves as a reference point). The reference station is placed where no vibrations or other disturbances in the signal are expected and in a sufficiently open place for better reception of the signal and more satellite signals. Fig 3 shows the base or reference station for the measurement.

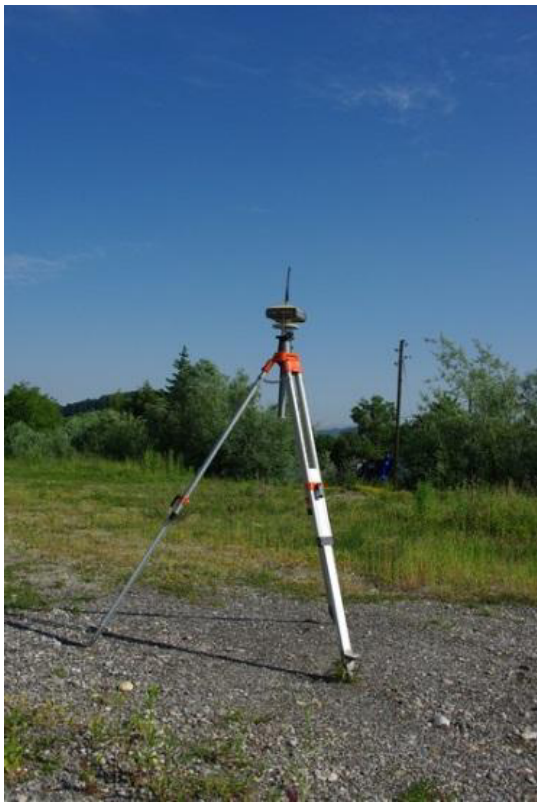

Fig. 3. Reference station - base.

A mobile receiver or rover is placed at the facility under investigation (Fig 4). It should be placed in the middles of the spans where the greatest displacements can be expected. 


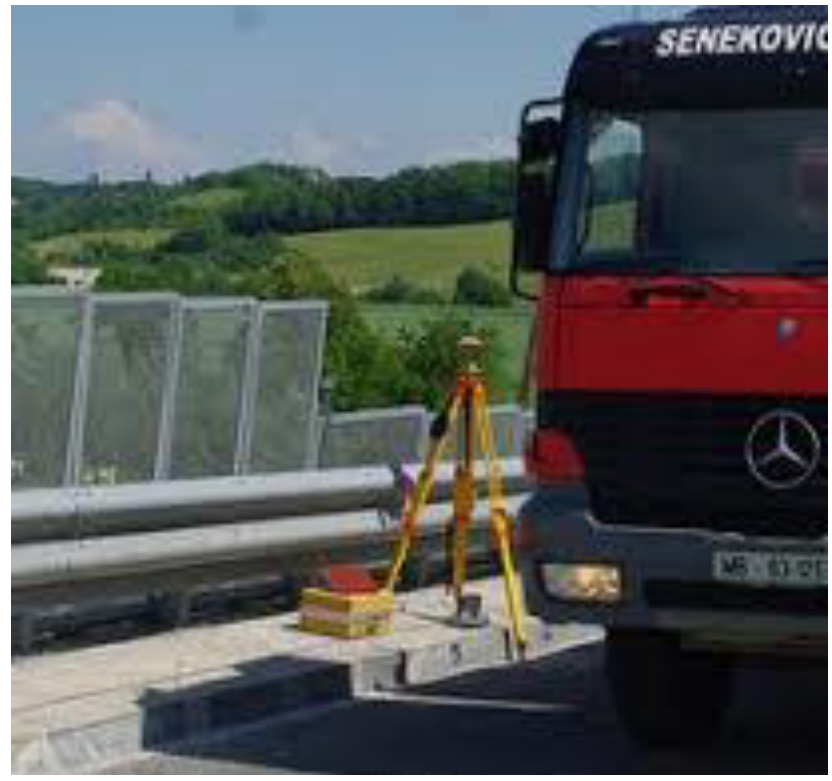

Fig. 4. Mobile satellite receiver - rover.

The reference receiver has a permanent coordinate during measurements. The mobile receiver (rover) records the coordinates according to bridge movements. A rover also orients the reference receiver and not only to satellites (with radio link) to obtain better accuracies of the coordinates (Fig 5).

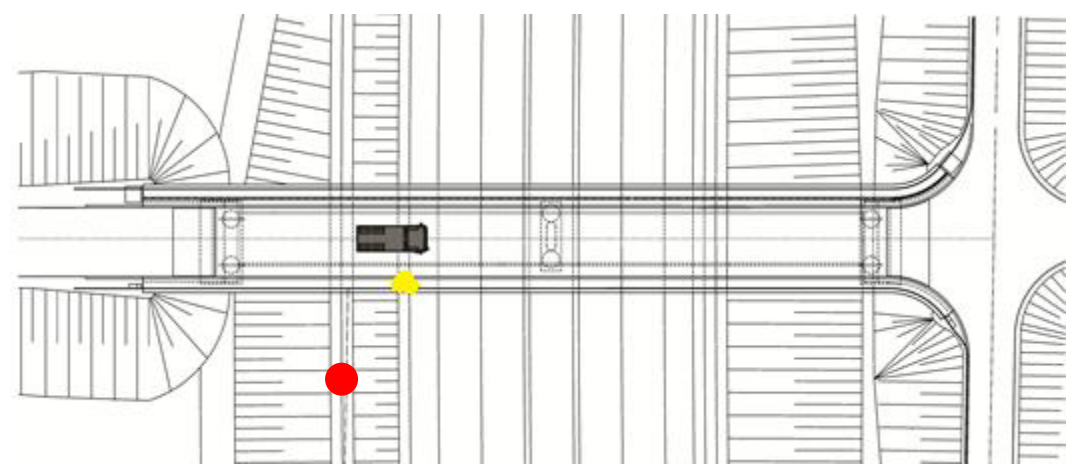

Fig. 5. Terrain and GNSS base (red) and rover (yellow) position.

GNSS data processing follows after completing the measurements as data on the field does not yield the values of displacements. After there are unexpected problems such as insufficient number of readings, signal interference, interrupting of measurements, excessive differences, multipath...

\subsection{Levelling method}

The movements of the right and left-sides of the bridge were monitored using the levelling method. Three points on each side were monitored. One of them on the embankment, which was the reference point, and two points at the centers of both spans where the load (truck) was standing at a static part of the investigation (Fig 7). DiNi 21 and Leica Sprinter levels were used (Fig 8, 9). 


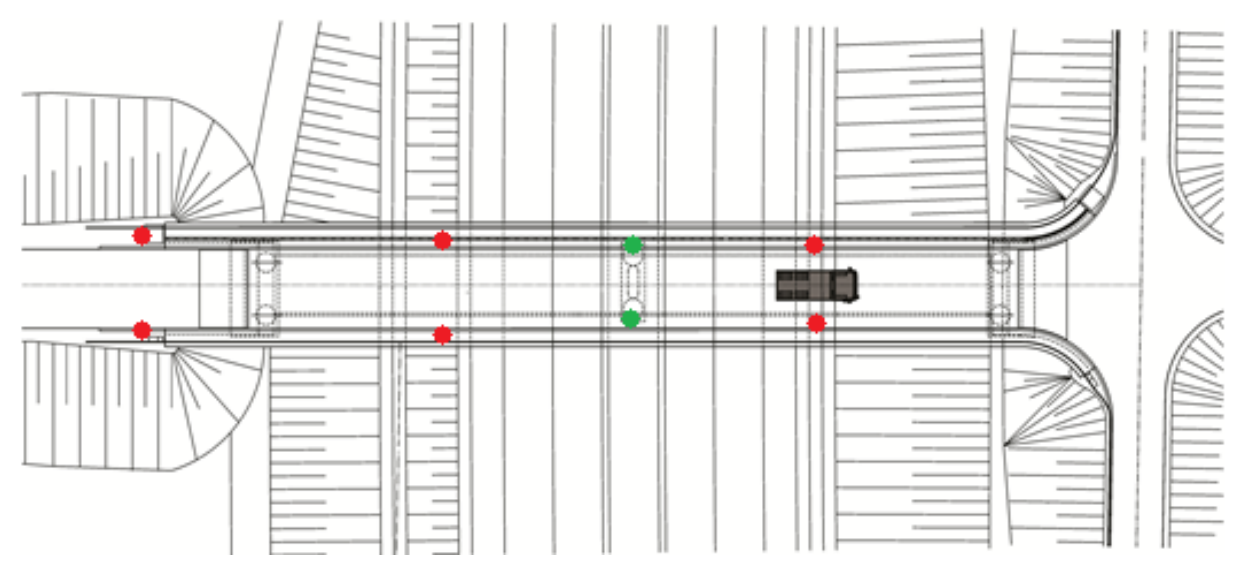

Fig. 6. Levelling points and locations of levels.

- Bench marks

- levels

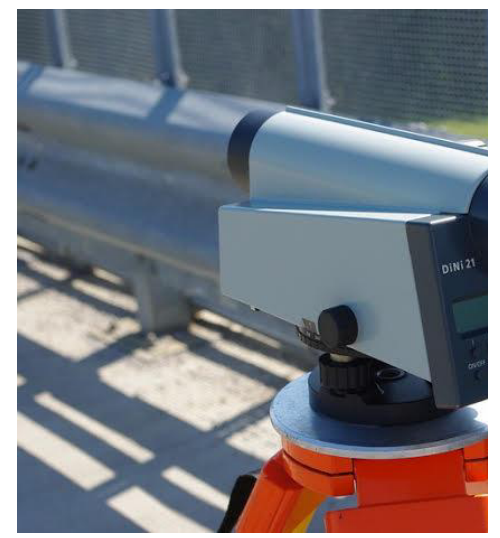

Fig. 7. DiNi 21 level.

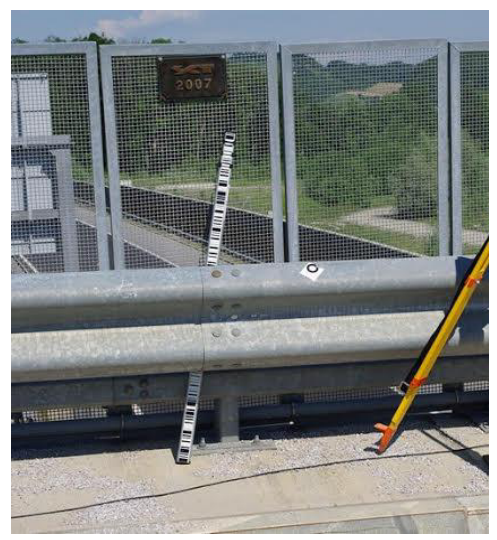

Fig. 8. Leica Sprinter level.

\section{Results and discussion}

All the results obtained from the analysis should be adequately treated. In such a manner any human error can be eliminated: double observations of the same point, wrong order of the point observation... Each phase is compared with the "zero" state (empty bridge with no burden), which was performed at the beginning of the measurement or with an independent point that is located outside of the deformation zone. For each object (left and right) separately, a comparison is made between the calculated and measured maximal vertical displacements. After the measurements accurate data processing, analysis and correct presentation is made.

In Tables 1 and 2 and Fig. 6 there are examples of the recorded measurements. The receiver records the spatial coordinates $\mathrm{x}, \mathrm{y}$ and $\mathrm{z}$ or $\mathrm{h}$ (height). In the case of determining movements in the load test of most interest is the height coordinate at which we know that the method is less accurate. 
Table 1. Some of coordinates obtained in the field.

\begin{tabular}{|c|c|c|c|}
\hline Point & $\mathbf{y}$ & $\mathbf{x}$ & $\mathbf{h}$ \\
\hline base & 552564.529 & 161175.309 & 266.322 \\
\hline 1 & 552572.333 & 161118.975 & 272.190 \\
\hline 2 & 552572.338 & 161118.974 & 272.191 \\
\hline 3 & 552572.336 & 161118.975 & 272.199 \\
\hline 4 & 552572.339 & 161118.977 & 272.193 \\
\hline 5 & 552572.338 & 161118.978 & 272.188 \\
\hline
\end{tabular}

During the processing procedure the receiver writes the initial 123 points and then the record jumps to the 4724th point. The records of all intermediate points between these two points are been lost.

Table 2. Missing records between 23 and 4724 .

\begin{tabular}{|c|c|c|c|}
\hline Point & $\mathbf{y}$ & $\mathbf{x}$ & $\mathbf{h}$ \\
\hline 22 & 552572.339 & 161118.970 & 272.163 \\
\hline 23 & 552572.337 & 161118.967 & 272.171 \\
\hline 4724 & 552572.329 & 161118.978 & 272.204 \\
\hline 4725 & 552572.332 & 161118.980 & 272.205 \\
\hline 4726 & 552572.330 & 161118.978 & 272.206 \\
\hline
\end{tabular}

The results showed what occurred during the measurements the received losses of the signal or incorrectly written data to the disc. Information about the movements was lost and only 572 points were written. All measurements were 5273 but 4701 of them were not recorded. This means that only about 10 minutes at the 88 minutes of actual measurement were recorded, as the measurement was set to record points every second.

We made a partial analysis of the results using the data. The height of the point varies for one to two centimetres. At the specific load test height differences within the range of $2 \mathrm{~mm}$ were expected. It can be concluded that this method is insufficiently accurate and reliable for the determination of displacement within such small dimensions.

When measuring vertical displacement suing the GNSS method the equation below tells us how precise all the results we need for quality movements determinations. If centimeter movements are expected, we have to choose such equipment, that has a standard deviation $(\sigma f)$ of measurement equal to a quarter of the expected displacements.

In our case, where a few millimeters of movement were expected we should choose a receiver that detects movements with a standard deviation of one quarter of a millimeter.

$\sigma f-$ standard deviation

$$
\frac{\sigma f}{f}<\frac{1}{4}
$$

$f$ - expected displacement

The GNSS method at this load test didn't did not provide reliable results. The measurements were too small to conclude anything about the movements during the test.

The results of the measurements can be seen in Table 3 . 
Table 3. The results of the measurements on left and right side.

\begin{tabular}{|c|c|c|c|c|c|c|c|c|c|c|}
\hline side & \multicolumn{5}{|c|}{ Left side (Leica Sprinter 50) } & \multicolumn{5}{|c|}{ Right side (Trimble DiNi 21) } \\
\hline \multirow[b]{2}{*}{$\mathrm{h}(\mathrm{m})$} & $\mathrm{hfl}(\mathrm{m})$ & \multicolumn{4}{|c|}{ hfi-hfl (m) } & hfl (m) & \multicolumn{4}{|c|}{ hfi-hfl (m) } \\
\hline & reading & $\begin{array}{c}2 . \\
\text { phase }\end{array}$ & $\begin{array}{c}3 . \\
\text { phase } \\
\end{array}$ & $\begin{array}{c}4 . \\
\text { phase } \\
\end{array}$ & $\begin{array}{c}5 . \\
\text { phase } \\
\end{array}$ & reading & $\begin{array}{c}2 . \\
\text { phase }\end{array}$ & $\begin{array}{c}3 . \\
\text { phas } \\
\text { e }\end{array}$ & $\begin{array}{c}4 . \\
\text { phas } \\
\text { e }\end{array}$ & $\begin{array}{c}5 . \\
\text { phase }\end{array}$ \\
\hline $\begin{array}{c}\text { T1 - } \\
\text { emban } \\
\text { k. } \\
\end{array}$ & 3.3384 & $\begin{array}{c}+0.000 \\
3 \\
\end{array}$ & $\begin{array}{c}+0.000 \\
3 \\
\end{array}$ & $\begin{array}{c}- \\
0.0003 \\
\end{array}$ & $\begin{array}{c}- \\
0.0006 \\
\end{array}$ & 3.4814 & $\begin{array}{c}+0.001 \\
5 \\
\end{array}$ & $\begin{array}{c}+0.0 \\
010 \\
\end{array}$ & $\begin{array}{c}+0.0 \\
015 \\
\end{array}$ & $\begin{array}{c}+0.000 \\
4 \\
\end{array}$ \\
\hline $\begin{array}{c}\mathrm{T} 2- \\
\text { Span } 1\end{array}$ & 1.6036 & $\begin{array}{c}+0.001 \\
1\end{array}$ & $\begin{array}{c}- \\
0.0001\end{array}$ & 0.0000 & $\begin{array}{c}- \\
0.0006\end{array}$ & 1.7356 & $\begin{array}{c}+0.001 \\
7\end{array}$ & $\begin{array}{c}- \\
0.00 \\
12 \\
\end{array}$ & $\begin{array}{c}- \\
0.00 \\
11 \\
\end{array}$ & $\begin{array}{c}+0.001 \\
1\end{array}$ \\
\hline $\begin{array}{c}\text { T3 - } \\
\text { Span } 2\end{array}$ & 0.7446 & 0.0000 & $\begin{array}{c}- \\
0.0001\end{array}$ & $\begin{array}{c}+0.001 \\
0\end{array}$ & $\begin{array}{c}- \\
0.0003 \\
\end{array}$ & 0.8747 & $\begin{array}{c}- \\
0.0017\end{array}$ & $\begin{array}{c}+0.0 \\
007 \\
\end{array}$ & $\begin{array}{c}+0.0 \\
003 \\
\end{array}$ & $\begin{array}{c}+0.000 \\
1 \\
\end{array}$ \\
\hline
\end{tabular}

$\begin{array}{ll}\text { Phase 1 } & \text { Empty bridge } \\ \text { Phase 2 } & \text { Burden on span 1 } \\ \text { Phase } 3 & \text { Empty bridge } \\ \text { Phase } 4 & \text { Burden on span 2 } \\ \text { Phase 5 } & \text { Empty bridge }\end{array}$

As can be seen the results for vertical displacements were within the range from $0.3 \mathrm{~mm}$ to $1.7 \mathrm{~mm}$. These are extremely small displacements which we needed to regard as microdisplacements and should be processed very carefully.

These small amounts can be obtained using reliability of the equipment and the precisions of the measurements, so that measurements with a large redundancy number. Also equipment which allows us to monitor displacement of $0.1 \mathrm{~mm}$ should be used. GNSS is evidently not yet such equipment.

At load test one should use two mutually independent methods because it could happen that by using only one method one cannot obtain the relevant value.

\section{Conclusions}

The measurement results showed us how small the shifts on this bridge really were. In such a case it is easy to do inaccurate measurements or errors. While we strive for the best possible performance and accurate measurements, we can see that there are small discrepancies when comparing the left and right sides of the bridge. There are several reasons for that. Deviations usually occur due to the differences in an object's geometry. It could be the case that the object does not have precisely the same characteristics on both sides (different width of the sidewalk, bicycle path just on one side).

Results from both sides were within expectations. The more significant movements were during phase 2 and phase 4 at the moments when the object was loaded in the first and second spans.

The maximal recorded vertical displacement was $2 \mathrm{~mm}$ in the second phase of the load test. In other phases these vertical displacements were smaller or not measurable at all. The levelling method for the load tests still appears as a very reliable method for detecting small shifts, where as we have seen that the GNSS method is not an option. 


\section{References}

1. J. Albert, H.G. Mass, A. Schade, W. Schwarz, Pilot studies on photogrammetric Bridge deformation measurement (IAG, Berlin, 2002)

2. M. R. Chowdhury, C. J. Ray, NDT\&E, 36, 237-244 (2003)

3. P. A. Fuchs, G. Washer, S. Chase, M. More, Journal of performance of constructed facilities, (2004)

4. S. J. Gordon, D. Lichti, M. Stewart, J. Franke, Modelling point clouds for precise structural deformation measurement (SPRS, Istanbul, 2004).

5. A. Guarnieri, A. Vettore, F. Remondino, PFIG Working Week, may 22-27, Athens, Greece (2004)

6. D. V. Jauregui, R. K. White, C. B. Woodward, K.-R. Leitch, Journal of Bridge Engineering, 8, 212-222 (2003)

7. H.-G. Maas, U. Hampel, Photogrammetric Egineering \& Remote Sensing, 72, 1 (2006)

8. A. Marendić, Z. Kapović, R. Paar, Geodetski list, 3, 175-190 (2013)

9. T. Schäfer, T. Weber, P. Kyrinovič, INGEO 2004 and FIG Regional Central and Eastern European Conference on Engineering Surveying, Bratislava, Slovakia, nov 11$13,(2004)$

10. N. Harmati, Ž. Jakšić, M. Trivunić, V. Milovanovi, Periodica Polytechnica: Civil Engineering, 58(4), 431-444 (2014)

11. K. Krayushkina, O. Prentkovskis, A. Bieliatynskyi, R. Junevičius, Transport, 27(2), 129-137 (2012)

12. O. Prentkovskis, J. Tretjakovas, A. Vedas, A. Bieliatynskyi, A. Daninas, K. Krayushkina, Journal of Civil Engineering and Management, 18(5), 761-771 (2012)

13. A. Beljatynskij, O. Prentkovskis, J. Krivenko, Transport, 25(4), 394-402 (2010)

14. M. Starikov, A. Beljatynskij, O. Prentkovskis, I. Klimenko, Transport, 26(3), 255-262 (2011)

15. N. Kuzhel, A. Bieliatynskyi, O. Prentkovskis, I. Klymenko, S. Mikaliunas, O. Kolganova, S. Kornienko, V. Shutko, Transport, 28(4), 413-419 (2013)

16. K. Krayushkina, O. Prentkovskis, A. Bieliatynskyi, J. Gigineishvili, A. Skrypchenko, A. Laurinavičius, K. Gopalakrishnan, J. Tretjakovas, Baltic Journal of Road and Bridge Engineering, 11(1), 77-83 (2016)

17. I. Mrdak, M. Rakočević, L. Žugić, R. Usmanov, V. Murgul, N. Vatin, Applied Mechanics and Materials, 633-634, 1069-1076 (2014)

18. J. Ćetković, M. Knežević, M., Žarković, V. Murgul, N. Vatin, Applied Mechanics and Materials, 638-640, 2465-2470 (2014) 